\title{
Characteristics of Economic Literature and Its Translation
}

\author{
Jianjun Wang \\ Foreign Languages College, Inner Mongolia University, Hohhot, 010021, China \\ Yize Fan * \\ Foreign Languages College, Inner Mongolia University, Hohhot, 010021, China
}

\begin{abstract}
Since the system of socialist market economy established in China, the economy has experienced rapid growth and maintained a vigorous momentum in economic development during the past two decades. Meanwhile, many Western economic theories were introduced into China and applied for facilitating economic development. Therefore, the translation of economic literature plays an important role in helping to study economic theories. The paper summarizes linguistic characteristics of economic literature and puts forward the principles as well as requirements for translators in translating this kind of texts. Also, with economic development and Yu Xianghua's translation version as a case study, the authors analyze translation approaches and strategies in terms of terminology, long sentence and diagram.
\end{abstract}

Index Terms - economic literature, translation strategies, economic development

\section{INTRODUCTION}

Throughout the past 30-plus years of continuous exploration for reform and opening-up, China's economy has developed steadily and rapidly and made great achievement including that China's economy has risen from the sixth to the second place in the world in 2012. Since the establishment of socialist market economy, a number of famous economists and their theories, such as Wealth of Nation by Adam Smith, General Theory of Employment, Interest and Money by John Maynard Keynes and Principles of Political Economy by Alfred Marshall, etc, were introduced into China and translated and studied by many Chinese scholars. For this reason, the translation plays a more important role in promoting communication and cooperation with other countries under the circumstances of global economic development. Nowadays, a lot of classical theories of economics were translated into Chinese as textbooks applied for higher education. For instance, Principles of Economics translated by Liang Xiaomin, Economic Development translated by Yu Xianghua and Chen Xuejuan, etc. Western theories of economics have developed with successful economic development amid many countries in the past decades. Of course, these theoretical results also have positive effects on our country's economic growth. Therefore, the translation of economic theories which has a practical meaning to our economic work is of significance for those who want to study.

Although there are lots of good translation works in economic theories, we still need to study the relevant translation skills and principles reflected in translated economic texts. Compared with other subjects, economic literature characterized by profound linguistic and cultural connotation, epochal feature and disciplinary limit can be easily translated with mistakes. (Huang, 2008, p.111) During translation, we need to summarize characteristics of economic texts and apply translation principles to translation practice from which we try to learn something. "A translation of dynamic equivalence aims at complete naturalness of expression, and tries to relate the receptor to modes of behavior relevant within the context of his own culture; it does not insist that he understand the cultural patterns of the source language context in order to comprehend the passage." (Nida, 1964, p.159) Maybe we can integrate Nida's principle with specific translation skills to discuss how to translate economic texts, what principles and approaches we can use. Mainly on the example of Economic Development translated by Yu Xianghua and Chen Xuejuan, the authors analyze the characteristics and translation approaches through the case study of bilingual texts and put forward translation strategies of economic texts.

\section{CHARACTERISTICS OF ECONOMICS TEXTS}

\section{A. Brief Introduction to Economic Development}

Economic Development, written by Michael P. Todaro and Stephen C. Smith who are famous scholars in economic field, tells the differences of social economic conditions between developed and developing nations and gives the corresponding suggestion that can help developing countries to realize industrialization, poverty alleviation and economic prosperity. "The first goal is to ensure that students understand real conditions and institutions across the developing world. The second is to help students develop analytic skills while broadening their perspectives of the wide scope of the field. The third is to provide students with the resources to draw independent conclusions as they confront 
development problems, their sometimes ambiguous evidence, and real-life development policy choices — ultimately to play an informed role in the struggle for economic development and poverty alleviation." ( Todaro, 2005, p.18)

\section{B. Features of Economic Texts}

\section{Terminology}

There are a lot of terminology or technical words with specific meaning in the texts. These words and expressions loaded with special meanings are fixed and mainly used in economic texts. For example, externality (外部性), internalization (内化), present value (现值), and consumer surplus (消费者剩余), etc. Also, the words involving in expressions are simple and easy to understand. One example is closed economy. It is just made up by two simple words. On the other hand, we can find many expressions named after one's name. For instance, Gini Coefficient, Harrod-Domar Growth Model, Lorenz Curve and Malthusian Population Trap, etc. In the expression Gini Coefficient, Gini is a name of an Italian economist.

\section{Long Sentences}

There are many long sentences in the text. It is easy to find that in economic texts one sentence consists of several short pieces. For example, "however, in recent years, some scholars and practitioners, particularly from the developing world, argue that the impact of minimum wages on poverty is more nuanced in theory and practice, particularly when the possibility of income sharing among the poor is accounted for." (Todaro, 2005, p.243) This sentence includes five commas used to separate each part presenting different components mainly as adverbial in a whole sentence. Although one sentence is divided into several parts, it is not hard to understand. That is to say, it is complicated in form but simple in content. This kind of long sentence has a relatively complex structure which usually consists of several clauses or expressions with lots of modifiers and definitives. Sometimes, one paragraph is just comprised of one or two sentences. Thus, it makes the whole sentence look complicated and difficult to understand.

\section{Figures and Tables}

Figures and tables, playing an important role in economic texts, can vividly describe economic principles with least length and are popularized among economic literature. (Xie, 2007, p.75) They can clearly show the relations amid different economic variables and make complex theory or phenomenon more simplified and conspicuous. The English figures and tables are different from Chinese ones. As Economic literature always concerns about interest rates, economic growth, stocks, calculating, etc, which deal with plenty of concrete figures. (Huang, 2009, p.32) Figure refers to the graphic presentation of qualitative and quantitative data with rectangular coordinates involving horizontal axis, vertical axis and origin as well as the contents usually made by some lines, curves and numbers. Bar chart, pie chart, histogram and polygon mainly make up the figure. Also there are some pictures or irregular diagrams. Table refers to the written set of facts and numbers arranged in columns and rows. From that readers can specifically know the economic data generating by quantitative analysis.

\section{StRategies of Translation In ECONOMiC TEXTS}

\section{A. Translation Criteria}

Faithfulness is the primary consideration. The translator should be loyal to source language and then completely and accurately express the versions. In translation, it is not allowed to falsify, distort or delete source text on purpose. The second is expressiveness. A good translation work needs to be smooth and easy to understand. Except for these two fundamental factors above, we still consider normalization and specialization. Economic literature is the product of economic development. More translation works of economic literature came into being with the developed economy. Meanwhile, the problem of normalization in translation of economic terminology cannot be ignored. (Huang, 2008, p.111) In translation, particularly with regard to economic terminology, which is the core of the whole theory and has serious and specific meanings, translators are required to deeply understand its connotation and set proper translation version. Improper translation can lead to confusion of the meaning. Hence we have to attach high importance to the norm to avoid inaccurate translation. For example, CPI , an important gauge of the level of inflation, is the abbreviation of Consumer Price Index, which is translated into Chinese as “居民消费价格指数” rather than “消费者价格指数”. In the other hand, specialization is the manifestation of high-quality translation. Because of the disciplinary feature in economics, translation of terminology must be highly specialized. Common words and expressions, delivering economic problems, should be considered as terminology and show the specialization in the process of translation. (Guan, 2012, p.58) In addition, we had better eliminate the situation: one terminology with multiple translation versions. That is to say, one-to-one correspondence between one term and its translation is the good way to avoid the incomprehension caused by polysemy. Meanwhile, it can realize the unification between languages.

\section{B. Requirements for Translators}

Translators should not only have solid bilingual basic skills and rich experience in translation, but also have the profound background knowledge and know something about astronomy, geography, history, customs, economy, business, current affairs, literature and art. (Fu \& Tang, 2011, p.173) Therefore, when we translate economic literature, it is necessary for us to learn something about economics, which can help us better understand the source language and deeply analyze the economic facts to give good translation to the readers. A translator tends to conform to translation 
norms consciously or unconsciously in his or her translation process. By adopting the proper translation strategies, the translator conforms to various norms in the translation action, and promotes the ethical values which govern the translation norms. (Huang, 2009, p.3) Also, we need to master some translation strategies, and choose different translation approaches in translating different kind of texts. Only in that way can we make a good job in translation process.

\section{A Case Study of the Translation of ECONOMiC DEVELopment}

\section{A. Terminology Translation}

Terminology is the important component in economics. From Economic Development, we can find a lot of terminology. How to translate terminology can be illustrated by thoroughly discussing some examples from the Chinese version translated by Yu Xianghua and Chen Xuejuan.

The authors usually take the way of literal translation when translating economic terminology. For instance, translating “absolute poverty” into Chinese as “绝对贫困”, “complementary investment” as “互补性投资”, “surplus labor” as “剩余劳动力”, “capital accumulation” as “资本积累” and “multiple equilibria” as “多重均衡”. The translation of many of the terms adopts word-by-word translation which reflects the theory of equivalent translation. Translation consists in reproducing in the receptor language the closest natural equivalent of the source language message, first in terms of meaning and secondly in terms of style (Nida \& Tiber, 1969, p.12). In the first example "absolute poverty" defined by Todaro as: The situation of being unable or only barely able to meet the subsistence essentials of food, clothing, shelter, and basic health care. This term consists of one adjective used as modifier and one noun in form. We can know what the "absolute poverty" is from its definition, but it seems that we can directly translate this term in its literal meaning which can present the connotation itself, thus there is no need to consider too much about it deep meaning. Also the term "capital accumulation" consists of two nouns and we can easily know the first one "capital" just refers to a large sum of money and then we can get a proper translation directly by its correspondent meaning of the two words.

Although the literal translation has predominance in the terminology translation, there are still some terms translated with the approach of free translation. For example, the term "brain drain" is translated as “人才流失”. The first word "brain" generally refers to an organ inside one's head that controls how people think, feel and move or the ability to think clearly and learn quickly. (Longman Dictionary of Contemporary English, 2012, p.239) However , this meaning cannot be directly used to translate, like “大脑流失” or “智力流失”. The explanation of this term is that: The emigration of highly educated and skilled professionals and technicians from the developing areas to the developed areas. So we can clearly know the word "brain" refers to the highly skilled or professional people, not just organ or intelligence. Also this term has the same Chinese translation in Oxford Dictionary of Economics with Chinese Translation (2006, p.54), which gives the definition: a pejorative description of the tendency for talented people from poor countries to seek employment in richer ones. From the two definitions, apparently it is easy for us to find the key word in translating process. The second example is “disposable income”, translated as “税后收入”. For this term, we do not think much about translation of the word "income". What we need is to analyze the "disposable" which gives two explanations: one description is "intended to be used once or for a short time and then thrown away", the other is “available to be used”. The Chinese name is “一次性的，用完即丢弃的” and “可使用的，可支配的” respectively. The definition — the income that is available to households for spending and saving after personal income taxes have been deducted - it is obviously that the second description is more appropriate. There are people who translate this term just as “可支配收入”， but in Yu's translated version, he gives “税后收入” that is much closer to the definition particularly in the description — "after personal income taxes have been deducted" — in which the meaning of "after taxes deduction" cannot be better expressed just in the translation “可支配”.

Hence, both literal translation and free translation approaches can be used in dealing with the terminology translation. It is necessary for us to take account of definition or connotation of one term except for its superficial meaning. Only in this way can we get a proper translation and a comprehensive understanding of the terms.

\section{B. Long Sentence Translation}

In the text of Economic development, there are many long sentences with complex structure which makes readers feel obscure. So it is necessary to use some translation strategies in the process of converting source language into target language. Here are two examples from the text.

Example one. "If we assume that there is some direct economic relationship between the size of the total capital stock, $K$, and total GDP, $Y$ - for example, if $\$ 3$ of capital is always necessary to produce an annual \$1 stream of GDP - it follows that any net additions to the capital stock in the form of new investment will bring about corresponding increases in the flow of national output, GDP.” (Todaro, 2005, p.112)

Yu's translation: “我们假定在总资本存量 $K$ 和国内生产总值 $Y$ 之间存在着某种直接的经济关系, 比方说, 产出 1 美元的国内生产总值往往需要投入 3 美元的资本，那么就可以说以新投资的形式投入的资本净增加额将带来 国内生产总值相应规模的增长。”(Yu \& Chen, 2010, p.70) 
First we can see it is an adverbial clause of condition with two terms which are capital stock and GDP, signifying “资 本存量” and “国内生产总值” respectively. The sentence - for example, if \$3 of capital is always necessary to produce an annual \$1 stream of GDP - in its translation, the order is changed a little. Yu adjusted the word order and put the infinitive part first instead of word by word translation like “3 美元资本投入可以产出 1 美元 GDP”, which facilitates better understanding for learners and also can accord more with Chinese usage especially in economic texts.

Example two. "In the Lewis model, the underdeveloped economy consists of two sectors: a traditional, overpopulated rural subsistence sector characterized by zero marginal labor productivity - a situation that permits Lewis to classify this as surplus labor in the sense that it can be withdrawn from the traditional agricultural sector without any loss of output - and a high-productivity modern urban industrial sector into which labor from the subsistence sector is gradually transferred.” (Todaro, 2005, p.115)

Yu’s translation: “在刘易斯模型中, 欠发达的经济体由两个部门组成: 一个是传统、人口过剩、仅能维持生存 的农业部门, 这个部门的一个重要特征是劳动的边际生产率等于零。有鉴于此, 刘易斯把这部分从农业部门抽 出来但产出不会因此而有任何减少的劳动力称为剩余劳动力（surplus labor）。另外一个部门则是劳动生产率较 高的工业部门, 从维持生存的农业部门中转移出来的劳动力要逐渐转移进入该部门”。(Yu \& Chen, 2010, p.72)

It is a long sentence with participle structure and attributive clause. The strategies in translation, made by $\mathrm{Yu}$, include: (1) Separation. One sentence should be divided into three syntactic units and several sense groups rather than translating from the first word to the end, which makes the whole sentence more expressive and fluent. Next is to integrate each part to reorganize a translation order. For the translation of "sector characterized by ...", which is the structure of using past participle as postpositive attributive, $\mathrm{Yu}$ had segmentation on sentence which made "characterized by zero marginal labor productivity" as a new single clause in translation instead of translating it as a pre-attribute within one sentence. Another sentence is "into which labor from ...", which is an attributive clause and Yu also divided it into two sentences in its translation. (2) Semantic extension. Lewis model indicates two sectors and Yu translated it as “农业部 门” and “工业部门”. For the second one, Yu translated it as “工业部门” that is directly equivalent to the statement "industrial sector" from the sentence. While for the translation of the first sector's name, we cannot find any obvious word to define its name, but Yu just translated it as “农业部门” according to the description “traditional, overpopulated rural subsistence" and the expression of "industrial sector" which is correspondent to agricultural sector. Hence, the translator used a flexible approach translating concept based on its characteristics and context.

The two examples mentioned above, require the translators to have some background knowledge about economics which can help better understand texts particularly in its terminology. For the long sentences, involving several modifiers, coordinate components as well as postpositive attributives, which make translation more complicated. Therefore we have to carefully analyze the grammatical structure of long sentences and then give accurate translation by making use of some translation approaches.

\section{Diagram Translation}

Diagrams and tables are often found to make the complicated description or explanation simple, clear and conspicuous. "These diagrams adopted by Economic literature contribute to its clarity, conciseness, tidiness, conspicuousness and attractiveness." (Huang, 2009, p.32) In Economic Development, there are many figures and tables which specifically contribute to clear economic relations for readers. Tables always include data while figures, which can simplify the textual description or manifest the complex economic phenomenon, usually include lines, curves or other irregular shapes. As for the translation, take the following example to illustrate how to translate this kind of texts.

Example:

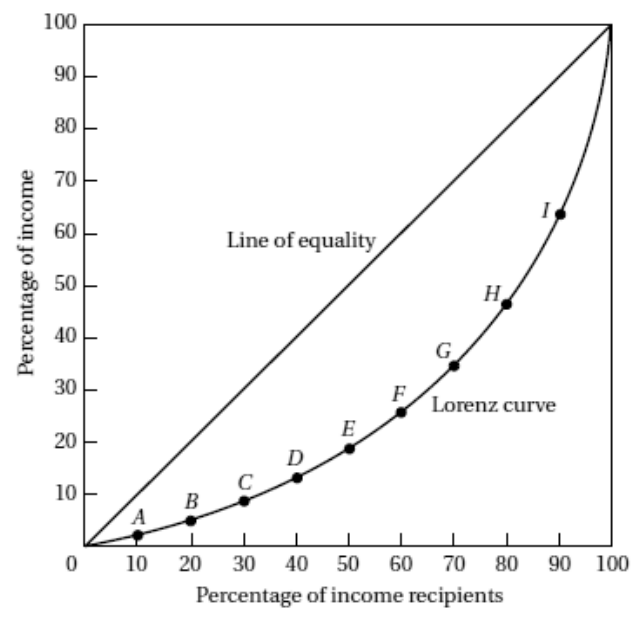

The Lorenz curve 
"Figure shows how it is done. The numbers of income recipients are plotted on the horizontal axis, not in absolute terms but in cumulative percentages. ... The vertical axis shows the share of total income received by each percentage of population. It is also cumulative up to $100 \%$, meaning that both axes are the same length. The entire figure is enclosed in a square, and a diagonal line is drawn from the lower left corner (the origin) of the square to the upper right corner. At every point on that diagonal, the percentage of income received is exactly equal to the percentage of income recipients." (Todaro, 2005, p.206)

Yu's translation:

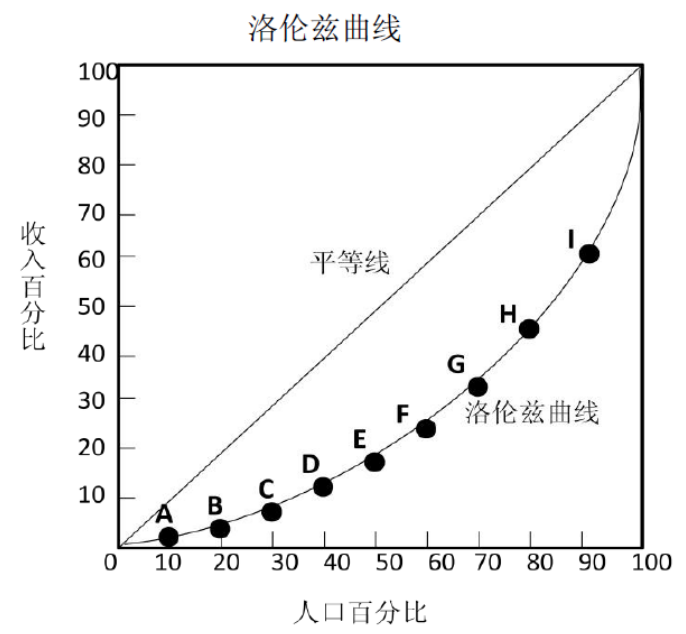

“图说明了构造洛伦兹曲线的方法, 它以收入群体为横轴（不是单独的比例，而是加总的比例）。……纵轴 表示每 $1 \%$ 人口的收入在总收入中所占的比例, 它也累计到 $100 \%$, 这意味着横轴和纵轴有相同的长度。整个图 形被封闭在一个方框中, 从左下方到右上方有一条对角线, 在对角线的每一点上, 收入的比例和人口的比例是 相同的。”( Yu \& Chen, 2010, p.127)

Figures, showing the basic concepts or principles, belong to information texts. In its translation process, the title of figures should be simple and clear to highlight the features of figures. Sometimes, we may have words extension. Just like the example above, Yu translated “percentage of income recipient” as “人口百分比” rather than “收入者百分 比”, because "income recipient", corresponding to "income", here just refers to population. Then, mainly on the basis of literal translation approach, we should concisely translate text and clearly deliver the economic facts manifested in the figure. Yu simply depicts the figure and does not have further explanations.

\section{CONCLUSION}

From the above, we can understand the significance of translating economic literature. Different texts require distinct translation criteria. In the translation of economic literature, we are supposed to think about normalization in technical words and specialization in common expressions. The translator who has the background knowledge of economics can do better in the translation of this field. From the case study of Todaro's work - Economic Development and its translation version, the paper summarizes the characteristics reflected in economic texts and analyzes the translation strategies in Yu's translation version, which mainly include terminology, long sentence and diagram translation. But because of various limitations, the paper cannot thoroughly discuss every characteristic and translation approach. However, we can know, for getting a good translation, what a translator needs do is to constantly accumulate specialized knowledge and keep having translation practice.

\section{REFERENCES}

[1] Bassnett, Susan \& Andre Lefevere. (2001). Constructing Cultures: Essays on Literary Translation. U.K.: Multilingual Matters Ltd.

[2] Bassnett, Susan. (2004). Translation Studies. Shanghai: Shanghai Foreign Language Education Press.

[3] Bao Mingjie \& Shen Xiaoyan. (2009). Translation of Economic Words. Contemporary Economics, (11), 126-127.

[4] Bell, R. (1991). Translation and Translating. London: Longman.

[5] Black, John \& He Yuchang. (2006). Oxford Dictionary of Economics with Chinese Translation. Shanghai: Shanghai Foreign Language Education Press.

[6] Fu Yanyan \& Tang Yanfang. (2011). Discussion about Translation of Economic Articles in Newspaper \& Journal from the Source Texts of the 23th Han Suyin Award for Young Translators. Overseas English, (12), 173-174.

[7] Gentzler, Edwin. (1993). Contemporary Translation Theories. London: Routledge.

[8] Gile, D. (1995). Basic Concepts and Models for Interpreter and Translator Training. Amsterdam and Philadelphia: John Benjamins.

[9] Guan Zhongming. (2012). Principles in Translation of Economic Terminology. English Teachers, (2), 57-62. 
[10] Huang Suqing. (2008). The Analysis of the Normalization of Economic Literature Translation. Journal of Hetian Teachers College, (6), 111-112.

[11] Huang Suqing. (2009). Translation Norms in Economic Literature from the Angle of the Translation Practice Principles of Economics. Hefei: Hefei Industry University.

[12] Longman Dictionary of Contemporary English (4th). (2012). Beijing: Foreign Language Teaching and Research Press.

[13] Ma Huijuan. (2005). The Diversification of Translation Standards in Business Text. Chinese Translators Journal, (3), 81-84.

[14] Munday, Jeremy. (2001). Introducing Translation Studies: Theories and Applications. London: Routledge.

[15] Newmark, P. (2001). Approaches to Translation. Shanghai: Shanghai Foreign Language Education Press.

[16] Nida, E.A. (1964). Toward a Science of Translating. Leiden: E.J. Brill.

[17] Snell-Hornby, Mary. (2001). Translation Studies: An Integrated Approach. Shanghai: Shanghai Foreign Language Education Press.

[18] Todaro, Michael P. \& Stephen C. Smith. (2005). Economic Development. Boston: Pearson Education Inc.

[19] Venuti, Lawrence. (1995). The Translator's Invisibility: A History of Translation. London: Routledge.

[20] Wang Tao. (2001). Practical Course of English-Chinese \& Chinese-English Translation. Wuhan: Wuhan University Press.

[21] Xie Guimei. (2007). The Translation of Figures \& Tables in Economics — From the Perspective of Functionalism. Journal of Language and Literature Studies, (8), 75-77.

[22] Xiu Changbai. (2008). English in Economics. Beijing: China Agriculture Press.

[23] Yang Dongfang. (2009). Exploration of Culture-loaded Words. Science and Technology Innovation Herald, (14), p.220-221.

[24] Yang Xiaoyan. (2010). Transformational Technique of Parts of Speech in Translation of English in Economics. Time Education, (9), 85-87.

[25] Yu Xianghau \& Chen Xuejuan. (2010). Economic Development. Beijing: China Machine Press.

[26] Zhou Fangzhu. (2002). Principles of Translation From English into Chinese. Hefei: Anhui University Press.

Jianjun Wang was born in Inner Mongolia, China. He is currently an associate professor in Foreign Languages College, Inner Mongolia University, China. His research interests include translation and intercultural communication.

Yize Fan was born in Inner Mongolia, China. He is currently a postgraduate in Foreign Languages College, Inner Mongolia University, China. His research interests include translation and intercultural communication. Email:1138190741@ qq.com 